\title{
Editorial
}

\section{Exploring Antarctica - a centennial perspective}

$\mathrm{W}$ e are embarked on a decade of celebrations of the national expeditions of what is now termed the Heroic Age. Exploring the Antarctic - the great unknown continent - a hundred years ago was great adventure and, given what we now know of the primitive state of their equipment, it is surprising that more of these explorers did not die. The tragic death of Captain Scott's polar party must be taken as a key talisman for the title "Heroic Age" but we should not underestimate the courage and fortitude of all the others - British, Swedish, Norwegian, French, German, Belgian, Argentinean, Polish, Romanian, American etc - who sailed, walked and sledged into the unknown for the greater good of their nation.

These days in the Antarctic we are no longer focussed simply on the achievements of nation states. Now we have recognised the importance of the Antarctic in a global context and, having invented Earth System Science as a framework to link our efforts, have discovered that the Antarctic is indeed a key piece of the jigsaw. How pleased our forbears these explorers would be to realise that their efforts and objectives to make discoveries are not so different from ours. For, despite the Antarctic Treaty and its internationalising of the continent, there is still that frisson of excitement in being the first to achieve a scientific goal there!

Some have concluded that the most important scientific legacy of the Antarctic is the discovery of the ozone hole and the Montreal Protocol that sprang from this. Whilst undoubtedly of great global and, especially, human significance there are other contenders for the prize of most important and /or interesting that spring from the work of the earlier expeditions. Surely the understanding of the breakup of Gondwana, the relocation of the southern continents and the establishment of the polar ice sheet is of more than passing significance? The fossils collected on the early expeditions helped to focus attention on that. Or perhaps the role of Antarctic deep bottom water in ocean circulation? Measuring oceanographic variables to establish a primary description of structure and currents was a key part of the ship-borne tasks for almost all of the early explorers.

What is surprising in looking back is the way in which Antarctica was assumed for so long to be an arcane backwater for scientists, of little or no value to most mainstream science thinking. In effect this attitude persisted for almost half a century until the International Geophysical Year generated new enthusiasm, mainly to fill in a gap in global knowledge rather than exploit the special features of the continent.

We should make sure we learn from this history - otherwise why would we bother to record it? History teaches us that most of the best ideas came about from the inspiration of individuals, that leadership was not something learned on courses and that the best management was there to help reach objectives and nurture talent rather than hinder progress and stifle initiatives. Many of those early explorers had not only to raise the money and equipment to go south but then spend years paying back their debts when they returned, often with great personal sacrifice. But they were their own men, accountable for their own dreams.

You may say that science is not like that anymore with its peer review systems, its complicated and sometimes never-ending red-tape, and demands for generating income rather than real steps forward in knowledge or understanding. Antarctic science is now funded by public money so surely all of this is right and proper? Perhaps, but only if you assume that trust in good ideas and good people, which produced so many Nobel Prizes in the past, is better replaced by accountability, audit and report writing.

DAVID WALTON 
https://doi.org/10.1017/S0954102005002701 Published online by Cambridge University Press 